\title{
Hepatoprotective Effect of Vitamin C (Ascorbic Acid)
}

\author{
Elias Adikwu', Oputiri Deo \\ ${ }^{1}$ Department of Pharmacology and Toxicology, Faculty of Basic Medical Sciences, College of Health Sciences, University of Port \\ Harcourt, Choba, Nigeria; ${ }^{2}$ College of Health Technology, Otuogidi-Ogbia, Nigeria. \\ Email: adikwuelias@gmail.com
}

Received October $25^{\text {th }}, 2012$; revised November $27^{\text {th }}, 2012$; accepted December $17^{\text {th }}, 2012$

\begin{abstract}
Human and animal studies have shown that some drugs and chemical agents have potential hepatotoxic effects. The hepatotoxic effect of drugs and some chemical agents is reported to be associated with the generation of reactive oxygen species (ROS). These ROS are reported to be associated with lipid peroxidation in the liver. This mechanism has led to continuous evaluation of the hepatoprotective effect of antioxidants in humans and animals. Among the antioxidants been evaluated is vitamin $\mathrm{C}$ which is a water soluble antioxidant. Reports have linked vitamin $\mathrm{C}$ with hepatoprotective property in animals and humans. It synergistic hepatoprotective effect with other antioxidants was also reported. Due to these reports a comprehensive literature review on the hepatoprotective property of vitamin $\mathrm{C}$ in humans and animals was performed. It was observed that vitamin $\mathrm{C}$ exhibited a reputable hepatoprotective effect in humans and animals. Research showed that vitamin $\mathrm{C}$ inhibited hepatotoxicity induced by drugs, heavy metals, organophosphate insecticides and some chemical agents. Vitamin $\mathrm{C}$ was reported to normalized levels of serum alanine aminotransferase, aspartate aminotransferase, gamma glutamine, alkaline phosphatase, lactate dehydrogenase and malondialdehyde and serum bilirubin in intoxicated animals. It potentiates the activities of free radical scavengers, superoxide dimutase, and catalase glutathione peroxidase thereby preventing microsomal lipid peroxidation, liver fibrosis, liver necrosis and hepatic inflammation. In humans vitamin $\mathrm{C}$ was reported to be beneficial in non alcoholic steatohepatitis and in patients with fatty liver disease. Hepatoprotective property of vitamin $\mathrm{C}$ is attributed to it antioxidant property. Vitamin $\mathrm{C}$ (ascorbic acid) which is a major water-soluble antioxidant is believed to decrease lipid peroxidation either directly or indirectly by regenerating vitamin $\mathrm{E}$. Vitamin $\mathrm{C}$ is an important free radical scavenger in extracellular fluids, trapping radicals and protecting biomembranes from peroxide damage. Vitamin $\mathrm{C}$ effectively scavenges singlet oxygen, superoxide, hydroxyl, water soluble peroxyl radical and hypochlorous acid. It is also reported to be an excellent source of electrons and therefore can donate electrons to free radicals such as hydroxyl and super oxide radicals and quench their activity. Vitamin $\mathrm{C}$ is an essential co-factor involved in many biochemical functions and acts as an electron donor or reducing agent. In this review it is observe that vitamin $\mathrm{C}$ has hepatoprotective effect which increases when co administered with other agents precisely antioxidants.
\end{abstract}

Keywords: Vitamin C; Hepatoprotection; Antioxidant

\section{Introduction}

Vitamin C was discovered by Szent-Gyorgyi (1928) [1] It is a six-carbon compound structurally related to glucose, consisting of two inter-convertible compounds: Lascorbic acid, which is a strong reducing agent, and its oxidized derivative, $\mathrm{L}$ dehydroascorbic acid. Vitamin $\mathrm{C}$ is found in citrus, soft fruits and leafy green vegetables. Kidney and liver are good animal-derived sources of vitamin C [2]. Vitamin C can be administered orally or intravenously [3]. It is well absorbed efficiently in the small intestine via a saturable active transport mechanism. Absorption efficiency of low oral doses of vitamin C (4 $64 \mathrm{mg}$ ) may be as high as $98 \%$, but decreases with increasing doses of the vitamin C. Vitamin $\mathrm{C}$ is widely distributed in all tissues of the body, with higher levels found in the adrenal glands, pituitary and retina. Kidney and muscle tissues have lower level of vitamin C [4]. Vitamin $\mathrm{C}$ is oxidized to dehydroascorbic acid, which is hydrolysed to diketogulonic acid and then oxidized to oxalic and threonic acid [5]. Oxidation to carbon dioxide occurs at high doses of vitamin C. Unmetabolized vitamin $\mathrm{C}$ and vitamin $\mathrm{C}$ metabolites, such as oxalate are largely excreted in the urine. Approximately $3 \%$ of a 60 $\mathrm{mg}$ oral dose is excreted in feces. More of the vitamin is excreted unchanged at higher levels of vitamin $\mathrm{C}$ intake $[6,7]$. Available data suggested that vitamin $C$ is not associated with significant adverse effects and there are no obvious specific key toxic endpoints for vitamin $\mathrm{C}$ dose given orally to healthy subjects. But high oral doses of 
vitamin $\mathrm{C}$ were reported to be associated with gastrointestinal effects like abdominal distention, flatulence, diarrhea and transient colic [8]. Vitamin C supplementation may be associated with an increased risk of calcium oxalate renal stones [9]. Vitamin $\mathrm{C}$ is hydrophilic and is an important free radical scavenger in extracellular fluids, trapping radicals and protecting biomembranes from peroxide damage. Vitamin $\mathrm{C}$ effectively scavenges singlet oxygen, superoxide, hydroxyl, water soluble peroxyl radical and hypochlorous acid [10]. It is also reported to be an excellent source of electrons and therefore can donate electrons to free radicals such as hydroxyl and super oxide radicals and quench their activity [11]. Vitamin $\mathrm{C}$ is an essential co-factor involved in many biochemical functions and acts as an electron donor or reducing agent. Vitamin $\mathrm{C}$ has been reported by researchers to have heaptoprotective property. This is said to be associated with it antioxidant property [12-15].

\section{Hepatoprotective Effect of Vitamin C (Ascorbic Acid)}

Reported researches showed that vitamin $\mathrm{C}$ has hepatoprotective property. This is linked to its antioxidative property. Vitamin $\mathrm{C}$ was reported to attenuate hepatic damage induced by some chemical agents especially in animals. This is supported by the work of Bashandy and Alwasel, (2011) [16]. They reported that vitamin C normalized levels of alanine aminotransferase, aspartate aminotransferase, alkaline phosphatase, blood hydroperoxide and malondialdehyde in liver of carbon tetrachloride intoxicated rats. The ability of vitamin $\mathrm{C}$ to prevent Carbon tetrachloride induced hepatotoxicity in rats was also reported by some authors $[17,18]$. Ascorbic acid reduced cypermethrin induced Cytotoxicity in rat hepatocytes by recovering $60 \%$ of glutathione and $54 \%$ decrease in gamma glutamyl transpeptidase. Ascorbic acid was also able to preserved $100 \%$ of cell integrity and modulated alanine aminotransferase and aspartate aminotransferase [19]. Similar observation was reported when deltamethrin $(1.28 \mathrm{mg} / \mathrm{kg})$ was administered to wistar rats. Alanine aminotransferase, aspartate aminotransferase, alkaline phosphatase and gamma glutamyl transpeptidase were significantly increased. Pretreatment with vitamin C (200 $\mathrm{mg} / \mathrm{kg}$ ) normalized the above mentioned parameters [20]. The hepatoprotective effect of vitamin $\mathrm{C}$ against organophosphate induced liver damage can be further buttress by the findings of Mossa et al. (2011) [21]. He and his co-researchers exposed rats to a mixture of organophosphate insecticides for 28 days. This induced liver toxicity via elevated levels of serum aspartate aminotransferase, Alanine aminotransferase, alkaline phosphatase and disruption of liver structure. Vitamin $\mathrm{C}$ supplementation was reported to attenuate the hepatotoxic effects induced by the mixture of organophosphate insecticides.
Similar observation was reported by Amballi et al. (2010) [22]. He and his co-workers evaluated the effect of vitamin $\mathrm{C}$ on short-term hematological and biochemical alterations induced by acute chlorphyrifos in wistar rats. They reported that vitamin $\mathrm{C}$ mitigated alterations in serum biochemical parameters via the normalization of alanine amino transferase, aspartate aminotransferase and alkaline phosphatase. Ozturk and his co-workers also reported the protective effect of ascorbic acid against hepatotoxic and oxidative stress caused by carbon tetrachloride in the liver of wistar rats [23]. These observations are contrary to the work of Kamel et al. (2012) [24]. They reported that Ascorbic acid was ineffective against the elevation of enzymes leakage (alanine aminotransferase and aspartate aminotransferase) induced by Carbon tetrachloride in liver cells from BRL3A cell line. Al-Attar (2011) [25], also evaluated the hepato protective effect of vitamin $\mathrm{C}$ on theoacetamide (organosulphur) induced liver cirrhosis in wistar rats. Chronic administration of theoacetamide for 10 weeks increased liver transaminases. Liver histopathology showed centrilobular necrosis, hepatic cell degeneration and necrosis with loss of nucleus. The administration of vitamin $\mathrm{C}$ attenuated theoacetamide induced hepatoxicity via normalization of biochemical and histopathological changes induced by theoacetamide. Fenvalerate an insecticide $(20 \mathrm{mg} / \mathrm{kg})$ was reported to induce liver toxicity in rats. Pretreatment with vitamin C $20 \mathrm{mg} / \mathrm{kg}$ for 30 days restored to near normal fenvaterate induced liver toxicity [26]. Similar effect was observed with Pretreatment using vitamin C against imidacloprid (systemic insecticide) induced oxidative stress in mice liver. It was observed that vitamin $\mathrm{C}$ pretreatment gave a better protection than post-treatment [27]. This agreed with the report of Omiama (2004) [28], who observed mild recovery in the liver of Japanese quail treated with vitamin $\mathrm{C}$ and imidacloprid. Supplementation with vitamin $\mathrm{C}, 25 \mathrm{mg} / 100$ gram body weight for 3 days in male guinea pigs ameliorated ethanol induced hepatotoxicity [29].

Some metals and heavy metals like copper, lead, chromium and cadmium are known to induce hepatic damage in animals and humans [30,31]. Some researchers have shown that vitamin $\mathrm{C}$ attenuated hepatic damage induced by these heavy metals. One of these researches was published by Banerjee and co-researchers. They reported that ascorbic acid combated arsenic induced oxidative stress in mice liver [32]. El-Demedash and his co-workers also posited that vitamin $\mathrm{C}$ ameliorated stannous chloride induced toxicity in the liver of male rabbits. Among other effects vitamin $\mathrm{C}$ decreased levels of free radicals and improved liver architecture in stannous chloride treated rats [33]. This agreed with the work of Yousef et al. (2007) [34]. He and his friends reported the protective effect of ascorbic acid against stannous chloride induced 
toxicity in rabbits. It was also reported that prophylactic use of vitamin $\mathrm{C}$ gave hepatoprotection against lead induced liver toxicity [35].

Furthermore administration of sodium fluoride 10 $\mathrm{mg} / \mathrm{kg}$ body weight and Aluminum chloride $200 \mathrm{mg} / \mathrm{kg}$ for 30 days decreased levels of glutathione, ascorbic acid and glutathione peroxidase in the liver of mice. Complete recovery occurred in all parameters after pretreatment with ascorbic acid [36]. Similar observation was reported by other scholars $[37,38]$. The report of Krishnamoorthy and Sangeetha gave credence to the hepatoprotective effect of vitamin $\mathrm{C}$ against metallic compounds induced liver toxicity. They found out that the co-administration of $300 \mathrm{mg} / \mathrm{kg}$ of sodium nitrate and $300 \mathrm{mg} / \mathrm{kg}$ of vitamin $\mathrm{C}$ ameliorated sodium nitrate induced lipid peroxidation in the liver of albino rats [39].

Drugs are chemical agents used for the treatment of ailments. Some drugs are known to have hepatotoxic effects in human and animals. Vitamin $\mathrm{C}$ has shown tremendous protective effect against drugs and chemical agents induced hepatotoxicity [40,41]. One of these reports was published by Awodele and Co-researchers. They observed that administration of vitamin C $8 \mathrm{mg} / \mathrm{kg}$ to rats for 90 days gave relative protection against rifampicin induced hepatotoxicity [42]. Also in the evaluation of the protective role of vitamin $\mathrm{C}$ on acetaminophen induced hepatotoxicity in mice, it was observed that ascobate esters showed protective effect against acetaminophen induced hepatotoxicity in mice [43]. Similar finding was reported by Peterson and Knodell in (1984) [44]. In their work they observed that ascorbic acid ameliorated acetaminophen and cocaine induced hepatic damage in mice. This result raised the possibility that ascorbic acid may be useful in preventing hepatic injury caused by some hepatotoxic drugs.

The hepatoprotective effect of vitamin $\mathrm{C}$ against drug induce hepatic damage was also reported by Remiao et al. (2004) [45]. He and his co workers reported that preincubation of freshly isolated and prepared rat hepatocytes suspension with ascorbic acid reverted N-methly-alphamethyldopamine induce hepatotoxicity. The protective effect of vitamin $\mathrm{C}$ against drug induce liver damage was further evaluated by Ergul and Co-researchers. They evaluated the effect of vitamin $\mathrm{C}$ on oxidative liver injury induced by isoniazid in rats. They found out that isoniazid induced liver injury is associated with oxidative stress and pretreatment with vitamin $\mathrm{C}$ reduced liver damaged induced by isoniazid in rats [46]. Pretreatment with vitamin $\mathrm{C}$ normalized aspartate aminotransferase and alkaline phosphatase in halothane induced hepatotoxicity [47].

Research showed that pretreatment with 50,100 and $200 \mathrm{mg} / \mathrm{kg}$ of vitamin $\mathrm{C}$ attenuated carbamazepine (50 $\mathrm{mg} / \mathrm{kg}$ ) provoked hepatotoxicity in rats [48]. Vitamin C was also reported to prevent oxidative stress in rats' liver induced by cisplatin [49]. This is supported by the evaluation of the prophylactic effect of vitamin $\mathrm{C}$ on cyclosporine-A induced liver toxicity in rats [50].

Cold ischemia and reperfusion of the liver may cause hepatic damage. Reports showed that vitamin C can mitigate cold ischemia and reperfusion induced liver damage. This can be seen in the findings of Park and Lee. They reported that cold ischemia/reperfusion of the liver elevated portal pressure, lactate dehydrogenase and purine nucleoside phosphorylase activities. These changes were attenuated at ascorbic acid concentration of 0.25 and 0.5 $\mathrm{mm}$. Increase in lipid peroxidation and mitochondrial swelling were prevented by $0.5 \mathrm{~mm}$ of ascorbic acid. But these changes were augmented at higher dose $(2 \mathrm{~mm})$ of ascorbic acid [51].

Similar observation was reported by Seo and Lee, (2002) [52]. They posited that ascorbic acid acts primarily as an antioxidant in hepatic warm ischemia/reperfusion at low doses but as a proxidant at high doses. It was also reported that ascorbic acid 2-glucoside prevented sinusoidal endothelial cell apoptosis in supercooled preserved grafts in rat liver [53]. Some scholars reported similar observations [54,55].

Dietary vitamin $C$ supplement may have protective effect on the liver and also improve hepatic function as reported by some researchers. This is supported by findings from the evaluation of vitamin $\mathrm{C}$ on lipid peroxidation and glutathione system in the normal guinea pig heart. It was observed that dietary vitamin $\mathrm{C}$ supplementation is able to increase global antioxidant capacity of guinea pig heart tissues [56]. Dietary vitamin C supplement was also reported to confer protective effect against endotoxin induced oxidative damage to protein in guinea pig liver. This seems mainly due to a direct increase in hepatic ascorbate levels in vitamin $\mathrm{C}$ exposed animals [57]. Dietary vitamin C supplement was reported to decrease endogenous protein oxidative damage and lipid peroxidation in the guinea pig liver [58]. Further study showed that administration of monosodium glutamate (food additive) at a dose level of $0.6,6$ and $60 \mathrm{mg} / \mathrm{kg}$ for 14 days increased serum alanine aminotransferase and aspartate aminotransferase dose dependently. These elevated parameters were reduced after pretreatment with vitamin C. Histopathological changes induced by monosodium glutamate were also ameliorated [59].

In 1960, Calleja and Brooks reported that acute hepatitis was treated with high doses of vitamin C. They further explained that the beneficial effects of vitamin $\mathrm{C}$ were observed in 63 cases of hepatitis treated with high doses of vitamin C (10 grams) daily for 5 days administered rectally or intravenously. The appearance of urobilinogen in the urine was reduced by $50 \%$ [60].

The protective effect of vitamin $\mathrm{C}$ on the liver was 
also studied by Willis in 1957. He found that vitamin C reversed fatty degeneration and acute non-fatty hepatocellular degeneration and promoted the laying of reticulum and collagen in the liver of scorbutic guinea pig [61].

\section{Synergistic Hepatoprotective Effect of Vitamin $C$ with Other Agents}

Vitamin $\mathrm{C}$ was reported to form synergy with other agents. One of the visible synergies is between vitamin $\mathrm{C}$ and vitamin $\mathrm{E}$. This is supported by the co-administration of vitamin C $200 \mathrm{mg}$ and E $200 \mathrm{mg}$ as food supplement administered for 7 days to ethanol intoxicated rats. This ameliorated ethanol induced hepatotoxicity via normalization of transaminases and inhibition of lipid peroxidation. Ethanol induced histopathological changes were also reversed [62]. This agreed with the report of Ozdil (2004) [63]. He discovered that co-administration of ascorbic acid, alpha tocopherol acetate and sodium selenate ameliorated ethanol induced liver damage in rats. Co-administration of vitamin $\mathrm{C}$, vitamin $\mathrm{E}$ and sodium selenate 250,250 and $0.5 \mathrm{mg} / \mathrm{kg}$ respectively for 30 days also prevented ethanol induced liver injury. This manifested through normalization of the functions of parameters like alanine aminotransferase, aspartate aminotransferase and some endogenous antioxidants [64].

Shalan et al. (2007) [65] reported that treatment of male rabbits with vitamin $\mathrm{C}(1 \mathrm{mg} / 100 \mathrm{~g}$ body weight) and vitamin $\mathrm{E}(1 \mathrm{mg} / 100 \mathrm{~g}$ body weight) for 2, 4, 6 and 8 weeks ameliorated ethanol induced hepatomegaly, apoptic DNA fragmentation in hepatocytes, normalized alanine aminotransferase and aspartate aminotransferase activities.

Oral pretreatment of rats with vitamin C $(0.02 \mathrm{~g} / 100 \mathrm{~g}$ bwt) and vitamin E $120 \mathrm{mg} / \mathrm{kg} 15$ minutes prior to daily nolvadex administration was reported to ameliorate histopathological, histochemical and ultrastructural changes induced by nolvadex in the liver of rats [66].

This research is in agreement with the findings of Soylu and co-researchers who evaluated the antioxidants effect of vitamin $\mathrm{E}$ and $\mathrm{C}$ in hepatic fibrosis in biliary obstructed rats. They reported that vitamin $\mathrm{C}$ and $\mathrm{E}$ at a dose level of $10 \mathrm{mg} / \mathrm{kg}$ and $15 \mathrm{mg} / \mathrm{kg}$ coadministered retarded hepatic fibrosis in biliary obstructed rats [67].

In 2003, Olivera and his colleagues studied the role of vitamin $\mathrm{C}$ and $\mathrm{E}$ in the prevention of non alcoholic fatty liver disease in choline deficient diet fed rats. They induced fatty liver disease in wistar rats using choline deficient diet. Administration of vitamin C $30 \mathrm{mg} / \mathrm{kg} / \mathrm{day}$ orally reduced oxidative stress and inhibited the development of liver steatosis in these animals [68]. The report of Olivera and his co-workers agreed with the findings of some researchers [69].

More insights on the synergistic hepatoprotective effect of vitamin C and vitamin E was reported by Tawfik and Al-badr (2012) [70]. They evaluated the protective effect of vitamin $\mathrm{C}$ and $\mathrm{E}$ on the adverse effects of monosodium glutamate on liver and kidney functions in adult rats. They observed that 0.6 and $1.6 \mathrm{mg} / \mathrm{kg}$ of monosodium glutamate impaired hepatic function in treated rats which was ameliorated after pretreatment with vitamin $\mathrm{C}$ $(0.3 \mathrm{mg} / \mathrm{kg})$ and vitamin $\mathrm{E}(0.2 \mathrm{mg} / \mathrm{kg})$. Combined antioxidant effect of vitamin $\mathrm{C}$ and $\mathrm{E}$ demonstrated cytoprotective effect against 4-ene valporic acid induced injury in cellular glutathione depleted hepatocytes [71].

Treatment with vitamin $\mathrm{C}$ and $\mathrm{E}$ also reduced methidathion (organophosphate insecticide) induced toxicity in rat liver. Elevated biomarkers were normalized by vitamin $C$ and vitamin $E$ [72]. In an histological examination of the protective effect of vitamin $\mathrm{E}$ and vitamin $\mathrm{C}$ in Cisplatin induced hepatotoxicity. Coadministered vitamin E $5 \mathrm{mg} \cdot \mathrm{kg}^{-1}$ and vitamin $\mathrm{C} 8 \mathrm{mg} \cdot \mathrm{kg}^{-1}$ to rats for 3 months reduced cisplatin induced hepatotoxicity [73].

Uboh and others investigated the effect of vitamin C and $\mathrm{E}$ against gasoline vapour-induced liver injury in rats. They reported that gasoline vapour caused a significant increased in serum alanine aminotransferase, aspartate aminotransferase, alkaline phosphatase and degenerative changes in structural architecture of the liver tissue. They further stated that administration of vitamin $\mathrm{C}$ and $\mathrm{E}$ normalized these changes [74].

Significant decrease in serum transaminases and serum bilirubin was observed in dimethoate intoxicated rats. Administration of combined dose of vitamin E, $200 \mathrm{mg}$ $\mathrm{kg}^{-1} \cdot \mathrm{day}^{-1}$ and vitamin $\mathrm{C} 200 \mathrm{mg} \mathrm{kg}{ }^{-1} \cdot \mathrm{day}^{-1}$ to the guinea pigs ameliorated dimethoate induced hepatotoxicity [75].

The synergistic effect of vitamin $\mathrm{C}$ and other antioxidants was further evaluated by Balasundaram (2010) [76]. He was able to show that administration of vitamin A (40,000 and 50,000 iu), L ascorbic acid (500 and 1000 $\mathrm{mg}$ ) and vitamin E succinate (200 - $500 \mathrm{mg})$ synergistically reduced the amount of azo-dye binding protein in the liver of rats treated with p-dimethylaminoazobenzene.

Reports showed that vitamin C and some agents' synergistically normalized diabetes induce hepatotoxicity. This can be seen from the work of Eze and others. They reported that Co-administered vitamin $\mathrm{C}$ and Zinc 100 and $50 \mathrm{mg} / \mathrm{kg}$ respectively restored alanine aminotransferase and aspartate aminotransferase function in diabetes induced hepatotoxicity [77]. This showed that vitamin $\mathrm{C}$ and Zinc may play an important role in the prevention of hepatocellular injury that may occur in diabetes. This is further supported by the findings of Hamden et al. 2009 [78]. He and co-researchers showed that vitamin $\mathrm{C}$ coadministration with vitamin $\mathrm{E}$ ameliorate oxidative stress, pancreatic and hepatic injury in alloxan diabetic rats.

The synergistic effect of vitamin $\mathrm{C}$ and Zinc was further evaluated in animals by Samir and his colleagues. 
They clearly stated that co-administration of vitamin C and Zinc during nickel intoxication reversed nickel induced oxidative stress in the liver of rats [79]. Similar synergistic effect between vitamin $\mathrm{C}$, vitamin $\mathrm{E}$ and $\mathrm{L}-$ methionine was observed against lead induced oxidative stress in the liver of rats $[80,81]$.

Vitamin $\mathrm{C}$, in combination with silymarin, has also been shown to effectively reduce the hepatotoxic effect of acute lead poisoning [82-84]. In an animal study using toxic amounts of lead $(500 \mathrm{mg} / \mathrm{kg}$ diet $)$, vitamin C (1 $\mathrm{mg} / 100 \mathrm{~g}$ body weight) and silymarin $(1 \mathrm{mg} / 100 \mathrm{~g}$ body weight) were supplemented in an attempt to inhibit genetic damage to hepatocytes and halt the onset of acute hepatitis. The combination of vitamin $\mathrm{C}$ with silymarin significantly normalized alanine aminotransferase, aspartate aminotransferase, gamma-glutamyl transpeptidase, alkaline phosphatase and mitigated histopathological liver damage [85].

This is in agreement with the findings of flora and other workers who observed that $250 \mathrm{mg} / \mathrm{kg}$ of vitamin C and dimercaptosucinic acid conferred protection against lead impaired hepatic function [86]. Wang and coworker in 2007 also evaluated the protective effect of Ascorbic acid and thiamine supplementation at different concentrations against lead induced toxicity in mice. They reported that administration of vitamin $\mathrm{C}$ and thiamine inhibited lead acetate induced apoptosis in mice liver.

In humans it was also reported that vitamin $\mathrm{E}$ formed synergystic hepatoprotective effect with some chemical agents. This can be seen from a placebo controlled double blind study by Harrison and colleagues who randomized 49 patients with biopsy-proven non alcoholic steatohepatitis. These patients received vitamin E $1000 \mathrm{IU}$ qd, vitamin C $100 \mathrm{mg}$ qd and placebo for 6 months. Biopsy revealed statistical significant improvement in score although inflammation grade remained unchanged [87].

Furthermore twenty eight patients were treated with vitamin E plus vitamin C while 29 patients received Ursodeoxycholic acid. It was found that vitamin $\mathrm{E}$ and $\mathrm{C}$ combination is effective in patient with non alcoholic fatty liver disease and is as effective as Ursodeoxycholic acid. It was concluded that vitamin $\mathrm{E}$ and $\mathrm{C}$ combination is safe, inexpensive and an effective treatment option for patients with fatty liver disease [88]. In a retrospective single centre study of 68 patients with non alcoholic steatohepatitis 38 patients were administered vitamin $\mathrm{E}$ (400 - $800 \mathrm{IU} /$ day) and vitamin C $500-1000 \mathrm{mg} /$ day while 30 patients served as control. It was observed that vitamin $\mathrm{E}$ and $\mathrm{C}$ produced significant improvement in aminotransferase [89].

Treatment of homozygous beta-thalassemic children with combined dose of vitamin C, E and A for 6 and 12 months led to improvement in liver function status of these patients [90]. Co-administration of vitamin C $1 \mathrm{~g}$, atrovastatin $20 \mathrm{mg}$ and vitamin E $1000 \mathrm{IU}$ in human subjects was reported to reduce the odds of having hepatic steatosis by $71 \%$ in healthy individuals with non- alcoholic liver disease at baseline of 4 years of active therapy [91]. The hepatoprotective effect of vitamin $\mathrm{C}$ is said to be associated with it oxidative property. Vitamin $\mathrm{C}$ is a water-soluble antioxidant which decreases lipid peroxidation either directly or indirectly by regenerating vitamin E, the major lipid-soluble antioxidant [92]. Vitamin $\mathrm{C}$ was also reported to scavenge aqueous reactive oxygen species (ROS) by rapid election transfer that inhibits lipid peroxidation [93]. In this work it is observed that vitamin C may have hepatoprotective effect. This hepatoprotective effect tends to increase synergistically when co administered with other agents precisely antioxidants.

\section{REFERENCES}

[1] I. B. Chatterjee, "The History of Vitamin C Research in India," Journal of Biosciences, Vol. 34. No. 2, 2009, pp. 185-194. doi:10.1007/s12038-009-0021-7

[2] T. Stangeland, S. F. Remberg and K. A. Lye, "Total Antioxidant Activity in 35 Ugandan Fruits and Vegetables,' Elsevier, Vol. 113, No. 1, 2008, pp. 85-91.

[3] S. J. Padayatty, H. Sun, Y. Wang and H. D. Riordan, "Vitamin C Pharmacokinetics: Implication for Oral and Intravenous Use," Annals of Internal Medicine, Vol. 140, No. 7, 2004, pp. 533-537.

[4] Expert groups on vitamins and mineral, 2003.

[5] T. R. Wandzilak S. D. D'Andre, P. A. Davis and H. E. Williams, "Effect of High Dose Vitamin C on Urinary Oxalate Levels," Journal of Urology, Vol. 151, 1994, pp. 834-837.

[6] M. Levine, C. Conry-Cantilena, Y. Wang, R. W. Welch and P. W. Washko, "Vitamin C Pharmacokinetics in Healthy Volunteers," Proceedings of the National Academy of Sciences, Vol. 93, No. 8, 1996, pp. 3704-3709. doi:10.1073/pnas.93.8.3704

[7] M. Levine, S. C. Rumsey, R. Daruwala, J. B. Park and Y. Wang, "Criteria and Recommendations for Vitamin C Intake," Journal of the American Medical Association, Vol. 281, No. 15, 1999, pp. 1415-1423. doi:10.1001/jama.281.15.1415

[8] E. Cameron and A. Campbell, "The Ortho-Molecular Treatment of Cancer, II, Clinical Trial of High Dose Ascorbic Acid Supplements in Advanced Human Cancer," Chemical and Biological Interactions, Vol. 9, 1974, pp. 285-315. doi:10.1016/0009-2797(74)90019-2

[9] M. Urivetsky, D. Kessaris and A. D. Smith, "Ascorbic Acid Overdosing: A Risk for Calcium Oxalate Nephrolithiasis," Journal of Urology, Vol. 147, 1992, pp. 12151218.

[10] N. Sminorff and G. L. Wheeler, "Ascorbic Acid in Plants Biosynthesis and Function," Critical Reviews in Biochemistry and Molecular Biology, Vol. 19, 2000, pp. 267290.

[11] A. Bendich, "Antioxidant Micronutrients and Immune 
Responses," In: Bendich and R. K. Chandra, Eds., Micronutrients and Immune Functions, Academy Sciences, New York, 1990, p. 175.

[12] L. R. McDowell, "Vitamins in Animal Nutrition Comparative Aspects to Human Nutrition Vitamin C," Academic. Press, London, 1989, pp. 93-131.

[13] H. Sies, W. Stahl and A. R. Sundquist, "Antioxidant Functions of Vitamins Vitamin E and C, Carotene and Other Carotenoids," Annals of New York Academy of Sciences, Vol. 669, 1992, pp. 7-20. doi:10.1111/j.1749-6632.1992.tb17085.x

[14] C. A. Burtis and E. R. Ashwood, "Tietz Textbook of Clinical Chemistry," 2nd Edition, WB Saunders Co., Philedelphia, 1994, pp. 1275-1512.

[15] S. P. Netke., M. V. Roomi, C. Tsao and A. Niedzwiecki, "Ascorbic Acid Protects Guinea Pigs from Acute Aflatoxin Toxicity," Toxicology and Applied Pharmacology, Vol. 143, No. 2, 1997, pp. 429-435. doi:10.1006/taap.1996.8091

[16] S. A. Bashandy and S. H. Alwasel, "Carbon Tetrachloride-Induced Hepatotoxicity and Nephrotoxicity in Rats: Protective Role of Vitamin C," Journal of Pharmacology and Toxicology, Vol. 6, No. 3, 2011, pp. 283-292. doi:10.3923/jpt.2011.283.292

[17] O. Ademuyiwa, O. Adesanya and O. R. Ajuwon, "Vitamin C in CC14 Hepatotoxicity-A Preliminary Report," Human Experimental Toxicology, Vol. 13, No. 2, 1994, pp. 107-109. doi:10.1177/096032719401300208

[18] T. Kataoka, Y. Nishiyama, K. Yamato, J. Teraoka, Y. Morii, A. Sakoda, Y. Ishimori, T. Taguchi and K. Yamaoka, "Comparative Study on the Inhibitory Effects of Antioxidant Vitamins and Radon on Carbon TetrachlorideInduced Hepatopathy," Journal of Radiation Research, 2012, pp. 1-10.

[19] P. Grajeda-Cota, M. V. Ramírez-Mares and E. González de Mejía, "Vitamin C Protects against in Vitro Cytotoxicity of Cypermethrin in Rat Hepatocytes," Toxicology in vitro, Vol. 18, No. 1, 2004, pp. 13-19. doi:10.1016/S0887-2333(03)00077-8

[20] S. Mongi, S. Mahfoud, M. Amel, B. Kamel and J. Abdelfattahel, "Protective Effects of Vitamin C against Haematological and Biochemical Toxicity Induced by Deltamethrin in Male Wistar Rats," Ecotoxicoogy and Environmental Safety, Vol. 74, No. 6, 2011, pp. 1765-1769. doi:10.1016/j.ecoenv.2011.04.003

[21] A. H. Mossa, A. A. Refaie and A. Ramadan, "Effect of Exposure to Mixture of Four Organophosphate Insecticides at No Observed Adverse Effect Level Dose on Rat Liver: The Protective Role of Vitamin C," Research Journal of Environmental Toxicology, Vol. 5, No. 6, 2011, pp. 323-335. doi:10.3923/rjet.2011.323.335

[22] S. F. Ambali, C. Onukak, S. B. Idris, L. S. Yaqub, M. Shittu, H. Aliyu and M. U. Kawu, "Vitamin C Attenuates Short-Term Hematological and Biochemical Alterations Induced by Acute Chlorphyrifos Exposure in Wistar Rats," Journal of Medicine and Medical Sciences, Vol. 1, No. 10, 2010, pp. 465-477.

[23] I. C. Ozturk, F. Ozturk and M. Gul, "Protective Effects of
Ascorbic Acid on Hepatotoxicity and Oxidative Stress Caused by Carbon Tetrachloride in the Liver of Wistar Rats," Cell Biochemistry and Function, Vol. 27, No. 5, 2009, pp. 309-315. doi:10.1002/cbf.1575

[24] H. H. Kamel, H. Azza, A. Walaa, M. S. Ahmed and A. H. Mohamed, "Protective Effect of Some Antioxidants against Ccl4-Induced Toxicity in Liver Cells from BRL3A Cell Line," Journal of American Science, Vol. 6, No. 10, 2010, pp. 992-1003.

[25] A. M. Attar, "hepatoprotective Influence of Vitamin c on Thioacetamide Induce Liver Cirrhosis in Wistar Male Rats," Journal of Pharmacology and Toxicology, Vol. 6, No. 3, 2011, pp. 218-233. doi:10.3923/jpt.2011.218.233

[26] H. K. Hussein, M. H. Elnaggar and J. M. Al-Dailamy, "Protective Role of Vitamin C against Hepatorenal Toxicity of Fenvalerate in Male Rats," Global Advanced Research Journal of Environmental Science and Toxicology, Vol. 1, No. 4, 2012, pp. 60-65.

[27] K. S. El-Gendy, N. M. Aly, F. H. mohammed, A. Kenawy and A. H. Sebae, "The Role of Vitamin C as Antioxidant in Protection of Oxidative Stress Induced by Imidacloprid," Food and Chemical Toxicology, Vol. 48, No. 1, 2010, pp. 215-221. doi:10.1016/j.fct.2009.10.003

[28] O. S. Eissa, "Protective Effect of Vitamin C and Glutathione against the Histopathological Changes Induced by Imidacloprid in the Liver and Testis of Japanese Quail," The Egyptian Journal of Hospital Medicine, Vol. 16, 2004, pp. 39-54.

[29] P. A. Abhilash, R. Harikrishnan and M. Indira, “Ascorbic Acid Supplementation Causes Faster Restoration of Reduced Glutathione Content in the Regression of AlcoholInduced Hepatotoxicity in Male Guinea Pigs," Redox Report, Vol. 17, No. 2, 2012, pp. 72-79. doi:10.1179/1351000212Y.0000000010

[30] V. Rajamanickam and N. Muthuswamy, "Effect of Heavy Metals Induced Toxicity on Metabolic Biomarkers in Common Carp (Cyprinus carpio L.)," Maejo International Journal of Science and Technology, Vol. 2. No. 1, 2008, pp. 192-200.

[31] M. M. El-Tohamy and W. S. El-Nattat, "Effect of Antioxidant on Lead-Induced Oxidative Damage and Reproductive Dysfunction in Male Rabbits," Journal of American Science, Vol. 6, No. 1, 2010, pp. 613-622.

[32] P. Banerjee, S. S. Bhattacharyya and N. Bhattacharjee, "Ascorbic Acid Combats Arsenic-Induced Oxidative Stress in Mice Liver," Ecotoxicology and Environmental Safety, Vol. 72, No. 2, 2009, pp. 639-649. doi:10.1016/j.ecoenv.2008.07.005

[33] F. M. El-Demerdash, M. I Yousef and M. A. Zoheir, "Stannous Chloride Induces Alterations in Enzyme Activities, Lipid Peroxidation and Histopathology in Male Rabbit: Antioxidant Role of Vitamin C," Food and Chemical Toxicology, Vol. 43, No. 12, 2005, pp. 1743-1752. doi:10.1016/i.fct.2005.05.017

[34] M. I. Yousef, T. I. Awad, F. A. Elhag and F. A. Khaled, "Study of the Protective Effect of Ascorbic Acid against the Toxicity of Stannous Chloride on Oxidative Damage, Antioxidant Enzymes and Biochemical Parameters in Rabbits," Toxicology, Vol. 25, No. 3, 2007, pp. 194-202. 
doi:10.1016/j.tox.2007.03.017

[35] S. Gajawat, G. Sancheti and P. K. Goyal, "Vitamin C against Concomitant Exposure to Heavy Metal and Radiation: A Study on Variations in Hepatic Cellular Counts," Asian Journal of Experimental Sciences, Vol. 19, No. 2, 2005, pp. 53-58.

[36] N. J. Chinoy, A. K. Sharma, T. N. Patel, R. Memon and D. D. Jhala Ahmedabad, "Recovery from Fluoride and Aluminium Induced Free Radical Liver Toxicity in Mice," Fluoride, Vol. 37, No. 4, 2004, pp. 257-263.

[37] N. J. Chinoy, "Studies on Fluoride, Aluminium and Arsenic Toxicity in Mammals and Amelioration by Some Antidotes," In: G. Tripathi, Ed., Modern Trends in Experimental Biology, CBS Publisher, New Delhi, 2002, pp. 164-193.

[38] A. Sharma and N. J. Chinoy, "Fluoride Induced Ultrastructural and Histopathological Changes in Liver of Mice and Its Reversal by Antidotes [Abstract]," Proceedings of International Conference on Probing in Biological Systems, Mumbai, 7-11 February 2000, p. 113.

[39] P. Krishnamoorthy and M. Sangeetha, "Hepatoprotective Effect of Vitamin C on Sodium Nitrite-Induce Lipid Peroxidation in Albino Rats," Indian Journal of Biochemistry and Biophysics, Vol. 45, No. 3, 2008, pp. 206-208.

[40] M. R. Al-shathly, M. I. Mujallid, E. A. Al-Sharif and M. M. Alqurashi, "The Preventive Effect of Vitamin C upon Added Methyl Tertiary Butyl Ether (MTBE) in Drinking Water on the Liver of Albino Mice," International Journal of Research in Chemistry and Environment, Vol. 2, No. 2, 2012, pp. 214-228.

[41] K. M. Gaafa, M. M. Badawy and A. A. Hamza, "The Protective Effects of Ascorbic Acid, Cimetidine, and Nifidipine on Diethyldithiocarbamate-Induced Hepatic Toxicity in Albino Rats," Drug and Chemical Toxicology, Vol. 34, No. 4, 2011, pp. 405-419. doi: 10.3109/01480545.2011.586035

[42] O. Awodele, A. Akintowa, O. V. Osunkalu and H. A. Coker, "Modulatory Activity of Antioxidant against the Toxicity of Rifampicin in Vivo," Instituto de Mediana Tropica de Sao Paulo, Vol. 52, No. 1, 2010, pp. 43-46. doi:10.1590/S0036-46652010000100007

[43] A. Mitra, V. C. Ravikumar, W. M. Bourn and D. R. Bourcier, "Influence of Ascorbic Acid Esters on Acetaminophen-Induced Hepatotoxicity in Mice," Toxicological Letter, Vol. 44, No. 1-2, 1988, pp. 39-46. doi:10.1016/0378-4274(88)90127-0

[44] F. G. Peterson and R. G. Knodell, "Ascorbic Acid Protects against Acetaminophen- and Cocaine-Induced Hepatic Damage in Mice,' Drug-Nutrient Interactions, Vol. 3, No. 1, 1984, pp. 33-41.

[45] C. M. Remião, F. Milhazes, N. Borges, F. Fernandes, E. Carvalho and F. Bastos, "The Toxicity of N-Methyl-Alpha-Methyldopamine to Freshly Isolated Rat Hepatocytes Is Prevented by Ascorbic Acid and N-Acetylcysteine," Toxicology, Vol. 5, No. 2-3, 2004, pp. 193-203.

[46] Y. Ergul, T. Erkan and H. Uzun, "Effect of Vitamin C on Oxidative Liver Injury Due to Isoniazid in Rats," Pediatrics International, Vol. 52, No. 1, 2010, pp. 69-74.
doi:10.1111/j.1442-200X.2009.02891.x

[47] A. Z. Karakilcik, A. Hayat, N. Aydilek, M. Zerin and M. Cay, "Effects of Vitamin C on Liver Enzymes and Biochemical Parameters in Rats Anesthetized with Halothane," General Physiology and Biophysics, Vol. 24, No. 1, 2005, pp. 47-55.

[48] S. Thakur and E. Maheswari, "Carbamazepine Provoked Hepatotoxicity: Attenuation by Vitamin C," 2nd International Conference on Medical, Biological and Pharmaceutical Sciences, Singapore City, 28-29 April 2012.

[49] M. H. Omar, E. A. Ahmed, S. Abdel-Ghafar, S. Mohammed and A. Y. Nasser, "Hepatoprotective Effects of Vitamin C, DPPD, and L-Cysteine against Cisplatin-Induced Oxidative Stress in Male Rats," Journal of Biology and Earth Sciences, Vol. 2, No. 1, 2012, pp. 28-36.

[50] M. Mohsenikia, B. Hajipour, M. H. Somi, A. Khodadadi and M. Noori, "Prophylactic Effect of Vitamin C on Cyclosporine A-induced Liver Toxicity," Thrita Student Journal of Medical Scence, Vol. 1, No. 1, 2012, pp. 24-26.

[51] S. W. Park and S. M. Lee, "Antioxidant and Prooxidant Properties of Ascorbic Acid on Hepatic Dysfunction Induced by Cold Ischemia/Reperfusion," European Journal of Pharmacology, Vol. 580, No. 3, 2008, pp. 401-406. doi:10.1016/j.ejphar.2007.11.023

[52] M. Y. Seo and S. M. Lee, "Protective Effect of Low Dose of Ascorbic Acid on Hepatobiliary Function in Hepatic Ischemia/Reperfusion in Rats," Journal of Hepatology, Vol. 36, No. 1, 2002, pp. 72-77. doi:10.1016/S0168-8278(01)00236-7

[53] H. Matsukawa, T. Yagi, H. Matsuda, H. Kawahara, I. Yamamoto, J. Matsuoka and N. Tanaka, "Ascorbic Acid 2-Glucoside Prevents Sinusoidal Endothelial Cell Apoptosis in Supercooled Preserved Grafts in Rat Liver Transplantation," Transplantation Proceedings, Vol. 32, No. 2, 2000, pp. 313-317. doi:10.1016/S0041-1345(99)00967-7

[54] M. O. Taha, H. S. Souza, C. A. Carvalho, D. J. Faqundes, M. J. Simoes, N. J. Novo and A. Caricati-Neto, "Cytoprotective Effects of Ascorbic Acid on the IschemiaReperfusion Injury of Rat Liver," Transplantion Proceedings, Vol. 36, No. 2, 2004, pp. 296-300.

[55] V. De Tata, S. Brizzi, M. Saviozzi, A. Lazzarotti, V. Fierabracci, G. Malvaldi and A. Casini, "Protective Role of Dehydroascorbate in Rat Liver Ischemia-Reperfusion Injury," Journal of Surgical Research, Vol. 123, No. 2, 2005, pp. 215-221. doi:10.1016/j.jss.2004.08.008

[56] C. Rojas, S. Cadenas, R. Pérez-Campo, M. López-Torres and G. Barja, "Effect of Vitamin C on Antioxidants, Lipid Peroxidation, and GSH System in the Normal Guinea Pig Heart," Journal of Nutritional Science Vitaminology Tokyo, Vol. 40, No. 5, 1994, pp. 411-420.

[57] S. Cedenas C. Rojas and G. Barja, "Endotoxin Increases Oxidative Injury to Proteins in Guinea Pig Liver: Protection by Dietary Vitamin C," Pharmacology and Toxicology, Vol. 82, No. 1, 1998, pp. 11-18. doi:10.1111/j.1600-0773.1998.tb01391.x

[58] G. Barja, M. López-Torres, R. Pérez-Campo, C. Rojas, S. Cadenas, J. Prat and R. Pamplona, "Dietary Vitamin C Decreases Endogenous Protein Oxidative Damage, Ma- 
londialdehyde, and Lipid Peroxidation and Maintains Fatty Acid Unsaturation in the Guinea Pig Liver," Free Radical Biology and Medicine, Vol. 17, No. 2, 1994, pp. 105-115. doi:10.1016/0891-5849(94)90108-2

[59] M. A. Ibrahim, G. O. Buhari and A. B. Aliyu, "Amelioration of Monosodium Glutamate-Induced Hepatotoxicity by Vitamin C," European Journal of Scientific Research, Vol. 60, No. 1, 2011, pp. 159-165.

[60] H. B. Calleja and R. H. Brooks, "Acute Hepatitis Treated with High Doses of Vitamin C Report of a Case," Ohio State Medical Journal, Vol. 56, 1960, pp. 821-823.

[61] G. G. Willis, "The Influences of Ascorbic Acid upon the Liver," Canadian Medical Association Journal, Vol. 76, 1957, p. 1044.

[62] C. A. Oyinbo, W. N. Dare, G. R. A. Okogun, L. C. Anyanwu, N. M. Ibeabuchi, C. C. Noronha and O. A. Okanlawon, "The Hepatoprotective Effect of Vitamin C and $\mathrm{E}$ on Hepatotoxicity Induced by Ethanol in Sprague Dawley Rats," Pakistan Journal of Nutrition, Vol. 5, No. 6, 2006, pp. 507-511. doi:10.3923/pin.2006.507.511

[63] S. Ozdil, S. Bolkent, R. Yanardag and P. Arda-Pirincci, "Protective Effects of Ascorbic Acid, Dl-Alpha-Tocopherol Acetate, and Sodium Selenate on Ethanol-Induced Liver Damage of Rats," Biological Trace Element Research, Vol. 97, No. 2, 2011, pp. 149-162. doi:10.1385/BTER:97:2:149

[64] Y. Yanadarg, O. Ozsoy-Sacan, S. Ozdil and S. Bolkent, "Combined Effects of Vitamin C, Vitamin E, and Sodium Selenate Supplementation on Absolute Ethanol-Induced Injury in Various Organs of Rats," International Journal of Toxicology, Vol. 26, No. 6, 2007, pp. 513-523. doi:10.1080/10915810701707296

[65] M. G. Shalan, D. H. Abdaliw and A. G. Shalan, "The Protective Efficacy of Vitamins (C and E), Selenium and Silymarin Supplements against Alcohol Toxicity," World Rabbit Science, Vol. 15, No. 2, 2007, pp. 103-110

[66] F. A. Morsy, A. Gamal el Din, N. M. Shaffie and M. A. Badawi, "Histopathologic Study of the Antiestrogenic Nolvadex Induced Liver Damage in Rats and Vitamins Ameliorative Effect," Nature and Science, Vol. 8, No. 5, 2010, pp. 1-15.

[67] A. R. Soylu, N. Aydogdu, U. N. Basaran, S. Altaner, O. Tarcin, N. Gedik, H. Umit, A. Tezel, G. Dokmeci, H. Baloglu, M. Ture, K. Kutlu and K. Kaymak, "Antioxidants Vitamin E and C Attenuate Hepatic Fibrosis in Biliary-Obstructed Rats," World Journal of Gastroenterology, Vol. 14, No. 12, 2006, pp. 6835-6841.

[68] C. Oliveira, L. C. Gayotto, C. Tatai, B. I. Della Nina, E. S. Lima, D. Abdalla and F. P. Lopasso, "Vitamin C and Vitamin E in Prevention of Nonalcoholic Fatty Liver Disease (NAFLD) in Choline Deficient Diet Fed Rats," Nutrition Journal, Vol. 2, No. 9, 2003, pp. 1-5.

[69] G. O. Gullek, S. O. Guek and E. Altuntas, "The Effects of Methydatheon on Liver: Role of Vitamin E and C," Toxicology and Industrial Health, Vol. 19, No. 2-6, 2003, pp. 63-67.

[70] M. Tawfik and N. Al-Badr, "Adverse Effects of Monosodium Glutamate on Liver and Kidney Functions in Adult
Rats and Potential Protective Effect of Vitamins C and E," Food and Nutrition Sciences, Vol. 3, No. 5, 2012, pp. 651-659. doi:10.4236/fns.2012.35089

[71] M. Jurima-Rome, F. S. Abbott, W. Tang, H. S. Huang and L. W. Whitehouse, "Cytotoxicity of Unsaturated Metabolites of Valproic Acid and Protection by Vitamins C and E in Glutathione-Depleted Rat Hepatocytes," Toxicology, Vol. 112, No. 1, 1996, pp. 69-85. doi:10.1016/0300-483X(96)03352-5

[72] R. Sutcu, I. Altuntas, B, Yildirim, N. Karahan, H. Demirin and N. Delibas, "The Effects of Subchronic Methidathion Toxicity on Rat Liver: Role of Antioxidant Vitamins C and E,'’ Cell Biology and Toxicology, Vol. 22, No. 3, 2006, pp. 221-227. doi:10.1007/s10565-006-0039-7

[73] D. Califima, "Histologic Examination of the Protective Effect of Vitamin E and C in Cisplatin-Induced Hepatotoxicity," Trakya Universitesi Tip Fakultesi Dergisi, Vol. 22, No. 3, 2005, pp. 124-131.

[74] F. E. Uboh, P. E. Ebong, H. D. Akpan and I. F. Usoh, "Hepatoprotective Effect of Vitamin C and E against Gasoline Vapour Induced Liver Injury in Male Rats," Turkish Journal of Biology, Vol. 36, 2012, pp. 217-223.

[75] S. Y. A1-Awthan, A. M. A1-Douis, G. H. El-Sokkary and A. E. Aglan, "Dimethoate Induced Oxidative Stress and Morphological Changes in the Liver of Guinea Pig and the Protective Effect of Vitamin C and E," Asian Journal of Biological sciences, Vol. 5, No. 1, 2012, pp. 9-19.

[76] A. J. Velaganni and C. Balasundaram, "Effect of Antioxidant A, C and E and Their Analogues on Azo Dye Binding Proteins in Liver of Rats Treated with P-Dimethylaminoazobenzene," Indian Journal of Experimental Biology, Vol. 48, 2010, pp. 373-377.

[77] E. D. Eze, F. A. Dawud, A. A. Zainab, A. Jimoh, I. S. Malgwi and A. S. Isa, "Preliminary Studies of Effects of Vitamin C and Zinc on Some Liver Enzymes in AlloxanInduced Diabetic Wistar Rats," Asian Journal of Medical Sciences, Vol. 4, No. 1, 2012, pp. 17-22.

[78] K. Hamden, M. A. Boujbiha, H. Masmoudi, F. M. Ayadi, K. Jamoussi and A. Elfeki, "Combined Vitamins (C and E) and Insulin Improve Oxidative Stress and Pancreatic and Hepatic Injury in Alloxan Diabetic Rats," Biomedicine and Pharmacotherapy, Vol. 63, No. 2, 2009, pp. 9599. doi:10.1016/j.biopha.2008.02.001

[79] D. Samir, Z. Kechrid and M. R. Djabar, "Combined Protective Effect of Zinc and Vitamin $\mathrm{C}$ on Nickel-Induced Oxidative Liver Injury in Rats," Annals of Biological Research, Vol. 3, No. 7, 2010, pp. 3278-3286.

[80] R. Patra, D. Swarup and S. Dwivedi, "Antioxidant Effects of Tocopherol, Ascorbic Acid and L-Methionine on Lead Induced Oxidative Stress to the Liver, Kidney and Brain in Rats," Toxicology, Vol. 162, No. 2, 2001, pp. 81-88. doi:10.1016/S0300-483X(01)00345-6

[81] K. Ramanathan, B. Balakumar and C. Panneerselvam, "Effects of Ascorbic Acid and Alpha Tocopherol on Arsenic Induced Oxidative Stress," Human Experimental Toxicology, Vol. 21, No. 12, 2002, pp. 675-680. doi:10.1191/0960327102ht307oa

[82] M. G. Shalana, M. S. Mostafa and M. M. Hassouna, 
"Amelioration of Lead Toxicity on Rat Liver with Vitamin C and Silymarin Supplements," Toxicology, Vol. 206, 2005, pp. 1-15. doi:10.1016/j.tox.2004.07.006

[83] K. K. Das, S. N. Das and S. Das Gupta, "The Influence of Ascorbic Acid on Nickel Induced Hepatic Lipid Peroxidation on Rats," Journal of Basic and Clinical Physiology and Pharmacology, Vol. 12, No. 3, 2001, pp. 187-195. doi:10.1515/JBCPP.2001.12.3.187

[84] K. Chen, J. Suh and A. C. Carr, "Vitamin C Suppresses Oxidative Lipid Damage in Vivo, Even in the Presence of iron Overload," American Journal of Physiology, Endocrinology and Metabolism, Vol. 279, No. 6, 2000, pp. 1406-1412.

[85] M. Sabzevarizadeh and H. Najafzadeh, "Comparison Effect of Silymarin and Vitamin C on Liver Function in Myoglobinuric Status in Rats," World Applied Sciences Journal, Vol. 17, No. 2, 2012, pp. 228-232.

[86] S. J. Flora, M. Pande and A. Mehta, "Beneficial Effect of Combined Administration of Some Naturally Occurring Antioxidants (Vitamins) and Thiol Chelators in the Treatment of Chronic Lead Intoxication," Chemico-Biological Interactions, Vol. 145, No. 3, 2003, pp. 267-280.

[87] S. A. Harrison, S. Torgerson, P. Hayashi, J. Ward and S. Schenker, "Vitamin E and Vitamin C Treatment Improves Fibrosis in Patients with Nonalcoholic Steatohepatitis," American Journal of Gastroenterology, Vol. 98, No. 11, 2003, pp. 2485-2490. doi:10.1111/j.1572-0241.2003.08699.x

[88] G. Ersoz, F. Gunsar, Z. Karasu and S. Akay, "Manage- ment of Fatty Liver Disease with Vitamin E and C Compared to Ursodeoxycholic Acid Treatment," Turkish Journal of Gastroenterology, Vol. 16, No. 3, 2005, pp. 124128.

[89] M. Babich, "Efficacy of Vitamin E and Vitamin C in the Treatment of Nonalcoholic Steatohepatitis," Practical Gastroenterology, 2010, pp. 20-27.

[90] M. M. Attia, A. M. Sayed, F. A. Ibrahim, A. S. Mohammed and M. S. El-Alfy, "Effects of Antioxidant Vitaminson the Oxidant/Antioxidant Status and Liver Function in Homozygous Beta-Thalassemia," Romanian Journal of Biophysics, Vol. 21, No. 2, 2011, pp. 93-106.

[91] T. Foster, M. J. Budoff, S. Saab, N. Ahmadi, C. Gordon and A. D. Guerci, "Atorvastatin and Antioxidants for the Treatment of Nonalcoholic Fatty Liver Disease: The St. Francis Heart Study Randomized Clinical Trial," American Journal of Gastroenterology, Vol. 106, 2011, pp. 71-77. doi:10.1038/ajg.2010.299

[92] S. J. Padayatty, A. Katz, Y. Wang, P. Eck, O. Kwon, P. Eck, O. Kwon, J. H. Lee, S. Chen, C. Corpe, A. Dutta, S. K. Dutta and M. Levine, "Vitamin C as an Antioxidant: Evaluation of Its Role in Disease Prevention," Journal of the American College of Nutrition, Vol. 22, No. 1, 2003, pp. 18-35.

[93] B. Frei, L. England and B. N. Ames, "Ascorbate Is an Outstanding Antioxidant in Human Blood Plasma," Proceedings of the Natural Academy of Sciences, Vol. 86, No. 16, 1989, pp. 6377-6381. 